\title{
“UNA PAUSA DE HUMANIDAD EN MEDIO DE UN HORROR INFINITO". EUGENIO GONZÁLEZ Y ROBERTO MEZA: PRISIONEROS POLÍTICOS EN ISLA MÁS AFUERA
}

\author{
"A PAUSE OF HUMANITY IN THE MIDDLE OF AN INFINITE HORROR". \\ EUGENIO GONZÁLEZ AND ROBERTO MEZA: POLITICAL PRISONERS ON \\ THE ISLAND MÁS AFUERA
}

\author{
Pablo Fuentes Retamal \\ Universidad de Concepción \\ p.fuentes.retamal@gmail.com \\ Edson Faúndez Valenzuela \\ Universidad de Concepción \\ efaundez@udec.cl
}

\begin{abstract}
Resumen:
Este artículo estudia los relatos Más Afuera (1930) de Eugenio González y Los trágicos días en Más Afuera (1931) de Roberto Meza, testimonios de dos escritores prisioneros durante la dictadura de Carlos Ibáñez del Campo (1927-1931). El foco del análisis está puesto en las estrategias de resistencia que desplegaron los condenados en la isla Más Afuera para contrarrestar los efectos negativos asociados a su cautiverio. Analizaremos, en suma, las acciones individuales y colectivas que contribuyeron a preservar la integridad física y moral de quienes permanecieron confinados en un espacio de degradación y de horror.
\end{abstract}

Palabras clave: Literatura chilena, dictadura de Ibáñez, testimonio, resistencia, poder.

\begin{abstract}
:
This article studies the stories Más Afuera (1930) by Eugenio González and Los trágicos días en Mas Afuera. (1931) by Roberto Meza, the testimonies of two writers during the dictatorship of Carlos Ibáñez del Campo (1927-1931). The analysis focal point is concentrated on the resistance strategies that the prisoners on the island Mas Afuera deployed in order to counteract the negative effects associated with their captivity. Therefore, we will analyse the individual and collective actions which contributed to preserve the physical and moral integrity of those who stayed confined in such a horrible and humiliating place.
\end{abstract}

Keywords: Chilean Literature, Ibanez's dictatorship, testimony, resistance, power.

Recibido: 01 de marzo de 2021

Aceptado: 07 de junio de 2021 
Dossier. Pablo Fuentes Retamal, Edson Faúndez Valenzuela. "'Una pausa de humanidad en medio de un horror infinito'. Eugenio González y Roberto Meza: prisioneros políticos en Isla Más Afuera"

\section{Más Afuera y Los trágicos días en Más Afuera: testimonios de dos sobrevivientes}

El verdadero paradigma ético de nuestro tiempo es (...) el superviviente, que sin buscar justificaciones ideales "elige la vida" y lucha sencillamente por sobrevivir.

Giorgio Agamben, Lo que queda de Auschwitz.

La dictadura de Carlos Ibáñez del Campo (1927-1931) constituye un período de la historia chilena que no ha sido objeto de atención suficiente, a pesar de comprender un lustro fecundo en formulaciones ideológicas y agitación política. La carencia de estudios se debe, en parte, a la escasa documentación libre de censura, pues el ibañismo tuvo la precaución de silenciar a sus detractores (Flores 23). Este marco regulatorio y policial se explica a partir del precepto que el coronel Ibáñez dispuso durante su mandato, vale decir, robustecer el principio de autoridad y acentuar la demonización de los sectores disidentes, para

terminar definitivamente con la anarquía que ha reinado en el país. Si una vez en el ejercicio normal de mis funciones, los elementos anárquicos reaparecieran, propagando sus doctrinas disolventes, no vacilaré en pedir al Congreso las facultades necesarias para reprimirlos y encauzarlos. (cit. en Montero 104)

El régimen de Ibáñez prohibió todos los símbolos rebeldes ${ }^{1}$ y castigó severamente las conductas que promovieron el desacato. Los disidentes fueron confinados en prisiones políticas a lo largo de todo el país ${ }^{2}$, mientras que los ideólogos de la oposición fueron

\footnotetext{
${ }^{1}$ El régimen de Ibáñez prohibió los estandartes que incitaron al desacato. El historiador Jorge Flores se refiere a esta restricción, a propósito de la bandera roja: "no puede usarse como insignia dentro del territorio de Chile porque ella simboliza la anarquía y el desorden, el libertinaje y los peores horrores (...) Carabineros procederá contra los manifestantes que ostenten banderas rojas y les impedirá toda clase de manifestación, procediendo a destruir estas banderas" (24).

${ }^{2}$ Las ciudades que albergaron prisiones políticas fueron: Valparaíso, Concepción, Santiago, Rancagua, Arica, Copiapó, Limache, San Felipe, Puerto Montt y Constitución (Flores 24).
} 
encarcelados en algunas islas del Pacífico, principalmente en Pascua y Más Afuera ${ }^{3}$. Estas reclusiones políticas desarticularon por completo al bando opositor.

El historiador Jorge Flores considera que Más Afuera fue la prisión política más inhóspita y cruel de todo el régimen. Esta colonia penitenciaria albergó, en un mismo recinto, a "presos políticos junto con avezados delincuentes comunes" (40). Algunos de los prisioneros de este campo fueron el escritor Eugenio González, el poeta Roberto Meza, el senador Elías Lafertte, el diputado Gaspar Mora, y los dirigentes Alberto Baloffet, Pedro Arratia, Braulio León Peña, entre otros (Brescia 128).

La violencia ejercida en esta prisión por la máquina punitiva del régimen dictatorial le otorga a Eugenio González y a Roberto Meza el material humano y vivencial necesario para hacer del dolor una "experiencia comunicable" (Sarlo 26). De este modo, el novelista González textualiza su reclusión en el relato Más Afuera (1930), mientras que el poeta Meza hace lo propio en la bitácora Los trágicos días en Más Afuera (1931) ${ }^{4}$. Estos escritores, siguiendo a Giorgio Agamben, son "testigos", pues sobrevivieron a "una determinada realidad (...) y están en condiciones de ofrecer un testimonio" (15). Más Afuera y Los trágicos días en Más Afuera, desde esta perspectiva, son relatos testimoniales, cuyo propósito es visibilizar los fundamentos que comprueban la veracidad de un acontecimiento traumático ${ }^{5}$. Eugenio González y Roberto Meza, consecuentemente, se convierten en "actores inmediatos" de los hechos narrados (Prada, De lo testimonial 11), sujetos interpelados por la memoria, quienes cumplen una función vicaria: hablar en representación de aquellos prisioneros que murieron "en su lugar" (Sarlo 36).

Las lecturas críticas que abordan Más Afuera han estudiado, fundamentalmente, la prevalencia de la estética realista (Tapia 150); la angustia como soporte de las acciones narrativas (Concha 43); y la sobriedad de una prosa que no dramatiza en lo trágico ni en lo

\footnotetext{
${ }^{3}$ Blanca Luz Brum, escritora y pintora uruguaya, residente en Más Afuera, inició la campaña para renombrar la isla. El presidente Eduardo Frei Montalva acogió esta petición en 1966. Desde entonces, Más Afuera se nomina “Alejandro Selkirk" en honor al marinero escocés que fue abandonado en este lugar en el siglo XVIII. ${ }^{4}$ Roberto Meza publicó su testimonio en el periódico Las Últimas Noticias. Este relato se editó, diariamente, entre el sábado 1 de agosto y el miércoles 23 de septiembre de 1931.

${ }^{5} \mathrm{La}$ "visibilización de acontecimientos" emparenta al discurso testimonial con la autobiografía, pues ambos relatos comparten, en términos generales, un mismo objetivo: narrar un "hecho verdadero" (Prada El discurso testimonio 21). Además, tanto el relato testimonial como la autobiografía, fundan un "pacto implícito con el lector" que supone la "aceptación verídica" de los hechos narrados, consentimiento que no tolera ninguna clase de sospecha, porque esta es una condición sine qua non para ambos géneros (Klein 32).
} 
Dossier. Pablo Fuentes Retamal, Edson Faúndez Valenzuela. "UUna pausa de humanidad en medio de un horror infinito'. Eugenio González y Roberto Meza: prisioneros políticos en Isla Más Afuera"

sobrecogedor (Gómez 53). La más reciente lectura de Daniel Noemí (2013) vincula la vida de los prisioneros políticos con la fisonomía del territorio carcelario y sugiere que "la naturaleza funciona en Más Afuera como un espejo (...) de los personajes" (266).

Los trágicos días en Más Afuera sólo ha sido comentado por Luis Enrique Délano, quien se refiere a las consecuencias que produjo la bitácora del poeta Meza, tras la caída del régimen dictatorial de Ibáñez:

Entró una ventolera que todo lo sacudió (...) se inició un proceso periodístico y político a la dictadura. Mucha gente tenía cosas que decir. (...) Por esos días Meza Fuentes publicó un folletín en Las Últimas Noticias, sus memorias en Más Afuera. (Délano 107).

No tenemos noticia de un estudio crítico que establezca diálogos entre los testimonios de González y Meza, de modo que nuestra lectura, por lo menos desde esta perspectiva, contribuye a iluminar los signos distintivos de las textualidades testimoniales del período. Su valor reside en producir un sentido que ilumina las relaciones que se establecen entre escritura y poder en el contexto de un régimen dictatorial. Más Afuera y Los trágicos días en Más Afuera hacen visibles aquellas zonas que el poder totalitario condenó a la penumbra, invitándonos, entre otros aspectos, a evitar repeticiones dolorosas mediante la rememoración de un episodio conflictivo de nuestra historia, pero, también, a conocer algo más de nuestro presente a partir del examen de las huellas textuales que nos dona el pasado.

El objetivo que acoge esta investigación es, como ya se ha sugerido, estudiar las formas de resistencia que desplegaron los reclusos políticos en la isla-presidio, a partir de los testimonios previamente señalados. Esto implica identificar las estrategias que trazaron estos sujetos rebeldes para abrirse a otras formas y actividades de vida, producir un diálogo entre las escrituras examinadas y advertir los efectos políticos de los testimonios de González y Meza.

Los conceptos teóricos que orientan esta investigación derivan de la reflexión que desarrolló Michel Foucault en Vigilar y castigar (1975) y en No al sexo rey. Entrevista por Bernard Henry-Levy (1994) respecto del poder disciplinario y su capacidad para construir subjetividades y estructurar un orden normalizador. El poder, entendido una relación de 
fuerzas asimétricas, expresa un ejercicio disciplinante que afecta las subjetividades de los dominados por dicha fuerza, quienes siempre pueden contrarrestar los designios del poder mediante una estrategia precisa. Toda resistencia es, por lo tanto, coextensiva al poder, siendo tan inventiva, móvil y productiva como él. De este modo, es preciso que la resistencia "se organice, se coagule, se cimiente (...) y se distribuya estratégicamente" (Foucault, No al 162).

Nuestro ejercicio crítico, cuyo método se funda en el comentario de textos, en el establecimiento de diálogos intertextuales y en la posibilidad de vincular literatura y vida, incide en la creación de un espacio en la historia de la literatura chilena capaz de resguardar aquellos testimonios que portan signos de "humanidad en medio de un horror infinito" (Agamben 25). Los relatos de Eugenio González y Roberto Meza, además de producir un saber sobre tiempos aciagos, posibilitan el salto de la estética a la ética, enseñando que los sucesos individuales (la memoria individual), así como los colectivos, son indispensables para pensar nuestra identidad y curar de "toda fiebre a la sociedad" (Rancière 48).

\section{Estrategias de resistencia en Más Afuera de Eugenio González}

Proponerse no recordar es como proponerse no percibir un olor, porque el recuerdo, como el olor, asalta, incluso cuando no es convocado.

Beatriz Sarlo, Tiempo pasado.

Los carceleros que vigilan el campo Más Afuera someten a los prisioneros a una rutina "lenta, tediosa y abrumadora" (González 10). Estos sujetos disciplinarios, a quien Foucault llamaría "ingenieros de la conducta" (Vigilar 274), deben modelar el comportamiento de los reclusos para garantizar la sumisión de sus cuerpos y el control de sus conductas, sin embargo, este principio fracasa en la isla-presidio, pues la máquina punitiva despliega un ejercicio del poder que no se condice con un modelo disciplinario. Esta colonia penitenciaria recupera un esquema primitivo de reclusión que se limita a expulsar disidentes sin propiciar ninguna instancia de disciplinamiento ni reinserción. Esta fisura en el ejercicio del poder disciplinario invierte los roles en Más Afuera, de modo que la autoridad policial deviene en una maquinaria bárbara que renuncia a la disciplina, mientras que los reclusos ejercen una "disciplina positiva" que favorece las condiciones de vida que ofrece el campo Más Afuera. 
Dossier. Pablo Fuentes Retamal, Edson Faúndez Valenzuela. "UUna pausa de humanidad en medio de un horror infinito'. Eugenio González y Roberto Meza: prisioneros políticos en Isla Más Afuera"

El orden y la disciplina que cultivan los reclusos, elevándolos moralmente sobre sus carceleros, se expresan mediante diversas estrategias de resistencia al poder. En este sentido, las labores productivas son estrategias que despliegan los prisioneros para tolerar la violencia. El narrador destaca esta táctica en el texto mediante el uso de comillas latinas: "lo que mata es el aburrimiento, lejos de todo lo que a uno le gusta: el trago, las mujeres, «el trabajo»" (González 66). Las actividades laborales que registra el testimonio de Eugenio González son turnos de panadería, cocina y recolección de leña:

Mientras tanto acá, en el campamento, los panaderos cumplían a diario su tarea y los cocineros de turno preparaban el almuerzo (...) fueron sirviendo, rápido, a cada uno, mientras otros dos confinados les entregaban el pan. (27)

La autoridad militar ordena a los prisioneros mantenerse en los pabellones cuando una tormenta azota la isla. Los confinados políticos aprovechan estas ocasiones para atender algunas necesidades menores, por ejemplo, el cuidado y el zurcido de la ropa maltrecha (González 9). Estas actividades ocupan la atención de los confinados, manteniéndolos alejados de la improductividad que promueve el ocio.

La instrucción y el aprendizaje son otras estrategias de resistencia que alimentan el intelecto de los prisioneros. El narrador nos informa, en las primeras líneas de Más Afuera, que las bodegas del campo fueron acondicionadas para recibir los talleres de "carpintería y zapatería" (González 9). Estas instancias de aprendizaje siembran esperanzas en los confinados, optimismo que comprueba "Chute", un prisionero que planifica proyectos para los venideros "días de sol y libertad que presentía próximos" (González 19).

Los reclusos propician un clima de fraternidad, de proximidad con el otro, para contrarrestar la degradación moral que impone el poder en la isla-presidio. Esta deferencia se muestra, por ejemplo, cuando el narrador se refiere a un recluso que agoniza víctima de la tuberculosis. Los prisioneros establecen rondas de auxilio para socorrer las necesidades del compañero moribundo: "su muerte se podría producir de un momento a otro, los confinados organizaron turnos para acompañarlo durante la noche" (González 68). El siguiente fragmento de Más Afuera describe la alianza fraterna que rodea al enfermo: 
Consiguió permiso para cuidarlo y así se pasaba largos días, conversando, a ratos del pasado. Camañini tenía para su amigo enfermo una paciencia paternal. Cuando lo veía decaído o mal humorado, le contaba aquellas interminables y enredadas historietas que eran su fuerte, y se sentía feliz si lograba interesarlo. (González 20).

La solidaridad de los reclusos convoca la alegría y la risa que, desde un lugar diferente a la disciplina de los cuerpos que defiende el poder, produce pasajes de vida. Ese lugar es el del descontrol al orden establecido y el de las metamorfosis que actualizan los flujos corporales de la risa. En este contexto, el prisionero Camañini emplea el buen humor para alivianar la pesadumbre del compañero tuberculoso:

—Muérete luego, Chute, para que me dejes dormir. (...) Ya me tienes cabreado con tu maldita tos.

(...)

-Yo no me voy a morir de ésta. Te equivocas, Camañini... es el invierno el que me achuncha. Todavía tenemos que pasar juntos buenos ratos en el continente. A ti, ñato, te llevaré donde unas amigas que tengo en el Puerto para que sepas lo que son las mujeres... (González 14)

La risa es un recurso que resiste las estructuras de orden en la isla-presidio, con este propósito, algunos prisioneros se ocupan de mantener el buen ánimo de sus compañeros; por ejemplo, "El Perpetuo" danza cómicamente para desatar las carcajadas de sus camaradas: "bailaba quebrando la cintura y mirando de reojo, con languidez apasionada, al galán que le batía por todos lados el pañuelo ansioso. Las palmadas aumentaban en intensidad entusiasta" (González 81). Los prisioneros también organizan jornadas de baile para convocar la alegría, oportunidades que se celebran a escondidas del poder:

Algunos quebraban el cuerpo con agilidad filarmónica; otros muy tiesos parecían oficiantes de un rito; los que hacían de mujeres llevaban un brazo pulcramente colocado sobre el hombro de sus caballeros y éstos, inclinando el rostro, les conversaban en voz baja. (González 154)

Los carceleros desaprueban esta algarabía, convocando al orden en los pabellones mediante el tañido de un timbre: "El baile estaba en su apogeo cuando sonó la campana de recogida" (González 155). Este sonido es un signo visible de las estructuras de poder, un 
Dossier. Pablo Fuentes Retamal, Edson Faúndez Valenzuela. "'Una pausa de humanidad en medio de un horror infinito'. Eugenio González y Roberto Meza: prisioneros políticos en Isla Más Afuera"

llamado que ordena a los prisioneros paralizar los flujos de deseo, profundamente transgresivos, que residen en la emergencia de la risa.

Los prisioneros estiman que el canto es un catalizador que, al igual que la risa, consigue liberar las tensiones y contrarrestar la desesperanza:

- Cantemos, niños hay que alegrase.

(...)

La cuadra se llenaba de gritos, de exclamaciones, de risas. Los que estaban acostados se levantaron para incorporarse al júbilo común. (...) Era, pues, preciso cantar, echar fuera el alborozo del alma. Si hubieran tenido alcohol se habrían embriagado hasta quedar tendidos; pero en la isla sólo disponían del canto. (González 52)

Para entender cómo operan las estrategias de resistencia en la novela Más Afuera es fundamental recordar el episodio en que los prisioneros fundan el "Conjunto teatral Isla de Más Afuera" (González 144). Las actividades artístico-culturales que organiza y ejecuta esta agrupación estremecen las estructuras de orden que dicta la autoridad:

El Felpa se adelantó hacia el público y comenzó a cantar con voz bastante desafinada.

(...)

Anunciaron el segundo número: variedades por los hermanos Cabrero.

(...)

Vino, en seguida, un dúo de Endeíza y Bartolo.

(...)

Entonces entraron al escenario todos los elementos de la compañía y cantaron un coro fúnebre en recuerdo de los muertos en la isla.

(...)

El Felpa, (...) avanzó algunos pasos, sobándose con cierto embarazo las manos y dijo en tono de displicencia que iba a recitar un poema.

(...)

El número de fondo lo constituyó un sainete en el que aparecían diversos, hombres y mujeres, que hablaban cosas que nadie entendía, la concurrencia encontró entretenimiento, tratando de discernir quiénes eran los que trabajaban disfrazados de mujeres. (González 147-52)

El canto, los actos misceláneos, la declamación poética, la actuación y el baile son expresiones culturales que propician instancias de resistencia. Estrategias que otorgan sentido a una cotidianeidad extrema que resiste, no a través de ideologías ni discursos 
culturales organizados, sino que mediante actos o actitudes. Síntesis entre la disciplina, los flujos y metamorfosis corporales que iluminan zonas fundamentales de resistencia al poder.

\section{Estrategias de resistencia en Los trágicos días en Más Afuera de Roberto Meza}

El recuerdo irrumpe en el momento menos pensado (...) como una nube insidiosa que rodea el hecho que no se quiere o no se puede recordar.

Beatriz Sarlo, Tiempo pasado.

Las estrategias de resistencia que emplean los prisioneros políticos en el testimonio de Roberto Meza se resumen en las siguientes palabras: "hay que trabajar, levantarse temprano, ser útil, ayudar, escribir, leer" (Meza 87). El narrador evidencia estos recursos de sobrevivencia cuando solicita el beneplácito del teniente Eduardo Palma para incorporarse a las labores de panadería:

En las mañanas, con el pretexto de que lo hago para adelgazar, salgo a buscar leña cortada por mis compañeros de destierro. Al poco tiempo entro a trabajar como obrero a la panadería.

(...)

Y yo lo hago porque me da vergüenza estar de ocioso mientras los demás están sufriendo y trabajando. (Meza 84)

Los prisioneros valoran las actividades productivas. Debido a esto, una vez que todos los turnos están cubiertos, quienes se mantienen desocupados se las ingenian para atender cualquier labor que los reste del ocio, por ejemplo, Daniel Mery ${ }^{6}$ recicla algunos desechos para beneficiar a sus compañeros: "hace trabajos de hojalatería; con paciencia y buena voluntad transforma en elegantes faroles unos tarros de parafina" (Meza 178). Néstor Donoso $^{7}$ utiliza cartones, ramas y otros desechos para construir un tablero de ajedrez y sus respectivas piezas: "con la raquítica madera de lumilla (...) ha construido un juego de ajedrez. Así han salido unos rústicos caballos, alfiles, torres y reinas” (Meza 178). El

\footnotetext{
${ }^{6}$ Daniel Mery. Militante del Partido Comunista.

${ }^{7}$ Néstor Donoso Molina. Militante del Partido Socialista. Fundador de la Regional Socialista en Magallanes.
} 
Dossier. Pablo Fuentes Retamal, Edson Faúndez Valenzuela. "'Una pausa de humanidad en medio de un horror infinito'. Eugenio González y Roberto Meza: prisioneros políticos en Isla Más Afuera"

prisionero Rogelio Gaete ${ }^{8}$ no busca excusas en la tuberculosis que lo aqueja para ausentarse de sus obligaciones:

Advertimos en él una imagen anticipada de la muerte. Él lo sabe, pero no le importa (...). Y no le importa ir a la leña, ni hacer sus turnos de cocina (...) no busca en su enfermedad un pretexto para librarse de lo que hacen los demás. (Meza 214)

Roberto Meza no militó en un partido político, sin embargo, la mayoría de sus compañeros de reclusión participaron en conglomerados de corte marxista. Este vínculo partidista se evidencia en el siguiente diálogo:

Si tratamos de objetar algo se nos responde:

—Pero si ustedes están presos...

-Pero no somos delincuentes...

-Pero son comunistas...

(...)

Y estos comunistas de la isla son toda gente seria, trabajadora, organizada, sometida a una rígida y estricta disciplina. (Meza 163-4)

Esta identificación política explica por qué los prisioneros resisten los embates del poder mediante estrictas y fatigosas jornadas de trabajo. El investigador Juan Fraiman señala que la doctrina marxista considera que el trabajo es una actividad mediadora entre la naturaleza y el hombre, un proceso siempre "consciente y voluntario" (236). Por consiguiente, las relaciones productivas que ejercen los prisioneros son estrategias de sobrevivencia que custodian su integridad moral. Esta explicación teórica justifica las siguientes palabras del narrador: "en la isla los turnos son agradados. No se rompen" (Meza 196). Estamos ante una clara exaltación de la disciplina que, al igual como ocurre en el relato testimonial de Eugenio González, pretende invertir el orden axiológico que defiende el poder, el que se signa por la indisciplina, la violencia y la corrupción moral.

El trabajo es una estrategia de resistencia que se relaciona con otra forma de oposición al poder: la fraternidad. Los prisioneros complementan estos recursos para

\footnotetext{
${ }^{8}$ Rogelio Gaete. Militante ácrata. Estuvo recluido nueve meses en Más Afuera. Luego de su liberación, regresó a Santiago donde falleció aquejado de tuberculosis.
} 
resistir los designios del poder: "cada uno en su puesto, con una clara conciencia de su deber y su responsabilidad, nos comprendemos y nos sentimos amigos" (Meza 58). De este modo, las desavenencias ideológicas que, alguna vez, enemistaron a Roberto Meza con el dirigente José Rojas ${ }^{9}$ no tienen cabida en Más Afuera:

A decir verdad, nunca Rojas Marín tuvo por mí un sentimiento amistoso. Pero en la isla hemos convivido y los recelos de antes se cambian en un franco compañerismo (...) nacen (amistades) y se afianzan al embate implacable de los vientos contrarios. (Meza 130).

La fraternidad propicia un clima de respeto y compañerismo entre los penados que se refleja, por ejemplo, en el auxilio que los prisioneros otorgan a un camarada que padece en sus últimas horas de vida:

Hay (...) un hombre que agoniza. Es un tuberculoso. Pero no le falta en la agonía el consuelo de una amistad leal. Toda la noche y todas las noches, hay uno o dos compañeros que se turnan, que están a su lado velando. Sin miedo al contagio de la enfermedad los amigos no abandonan al hombre que va a dormir para siempre en esa isla distante de un hogar roto y despedazado por la desgracia. (Meza 106)

Compartimos la opinión del narrador de Los trágicos días en Más Afuera cuando señala que los confinados políticos, declarados "enfáticamente y oratoriamente ateos" (Meza 212), cobijan un sentimiento de amor y consuelo que recuerda "las enseñanzas del Evangelio" (Meza 212). Este vínculo fraterno explica el sentimiento del poeta Roberto Meza para con Elías Lafertte ${ }^{10}$ : “fue para mí un padre verdadero. Me enseñó a lavar la ropa (...). Paternalmente, ofrecía y me daba ayuda que, a través de los años y los acontecimientos, jamás podré olvidar" (Meza 121). Esta lealtad anuncia otra estrategia de resistencia, la higiene, pues el autocuidado constituye un acto de rebeldía en un espacio colmado de privaciones y suciedad.

\footnotetext{
${ }^{9}$ José Rojas. Dirigente comunista. Participó en el Comité Nacional de Asalariados. Fue presidente de la Unión Social Republicana de Asalariados de Chile.

${ }^{10}$ Elías Lafertte Gaviño (1886-1961). Militante del Partido Comunista. Discípulo y secretario personal de Luis Emilio Recabarren.
} 
Dossier. Pablo Fuentes Retamal, Edson Faúndez Valenzuela. "UUna pausa de humanidad en medio de un horror infinito'. Eugenio González y Roberto Meza: prisioneros políticos en Isla Más Afuera"

Los reclusos políticos organizan sus atuendos para resguardar la pulcritud de sus ropas. De este modo, las prendas de mejor calidad son embaladas para ser vestidas en el regreso a casa, mientras que los vestidos de uso cotidiano son aquellos que facilitan el ejercicio laboral, vale decir, overoles, pantalones anchos y delantales (Meza 246). No obstante, la rusticidad de estos últimos atuendos, su higiene exige un estricto protocolo de sanitizado que comprende jabonar, hervir, enjuagar, cepillar, estrujar y secar la ropa.

Hacemos una pequeña hoguera, (...) y en ella nuestra ropa hierve hasta despedir todas las fatigas (...). Después un baño de la ropa en agua fría con jabón mientras nosotros pasamos y repasamos a lo largo de toda su superficie el cepillo de quinaleja. (...) Estrujamos la ropa con toda nuestra fuerza hasta que no queda en sus pliegues una gota de agua. (...) $\mathrm{Al}$ viento, la ropa blanca flamea como una bandera. (Meza 245)

Michael Foucault indica en Vigilar y castigar que la disciplina se ocupa de todos los aspectos del individuo en el espacio penitenciario. Una maquinaria poderosa que impone una forma de vida que "regula el tiempo de vigilia, de actividad, de reposo, el número y la duración de las comidas, la calidad y la ración de los alimentos" (216). Esta es la forma de vida que asumen, voluntariamente, los reclusos de la isla Más Afuera para vencer los martirios que les impone el teniente Eduardo Palma, cifra del ejercicio violento y autoritario del poder. Recuérdese que la autoridad militar somete a los reclusos a una dieta estricta que sólo incluye "porotos" (Meza 206), suplicio que remite a las estrategias de control de las sociedades de soberanía (no de las sociedades disciplinarias), cuyo funcionamiento se sostuvo en la aplicación de instrumentos simples, pero capaces de evidenciar la presencia del soberano y su poder (Foucault Vigilar 122). Entonces, lo que pretende el teniente Palma cuando somete a los prisioneros a una dieta rigurosa es llevar, hasta su punto extremo, "la disimetría entre el súbdito que ha osado violar la ley y el soberano omnipotente que ejerce su fuerza" (Foucault Vigilar 47). Los penados que desarrollan labores en el rancho se las ingenian para resistir este pobre régimen alimenticio, perspicazmente elaboran distintos menús, a partir de una misma materia prima: "el cocinero nos sirve tres platos. Celebramos sonoramente su inventiva. Sólo le han dado porotos en la bodega y con ese artículo único crea tres platos para sus compañeros” (Meza 206). La mente lúcida, disciplinada y gozosa del cocinero elabora comidas refinadas con esas 
legumbres. Rescatamos en este ejercicio culinario la belleza que pervive en lo tosco, incluso, en la fealdad del terror:

A la hora de once hay una bandeja llena de unas sopaipillas doradas y fragantes que constituye para nosotros una sorpresa casi milagrosa.

(...)

Queda ahora el enigma de las sopaipillas. Al probarlas, advertimos en ella un gusto desconocido. Es una harina dorada, blanda, que se deshace suavemente en la boca. Todos estamos maravillados.

(...)

Quisimos darles esta sorpresa y, como era imposible conseguir harina, hemos fabricado nosotros mismos harina de porotos. (Meza 311)

La alegría y la risa también ocupan un lugar en la escritura de Meza. El poeta apunta en su bitácora: "el hambre, contra lo que pudiera creerse, nos pone de buen humor. Bien sabemos que nuestra desesperación será la alegría de nuestros carceleros” (Meza 207). Esta estrategia de resistencia se aprecia en otros pasajes de Los trágicos días en Más Afuera: "Una letrina suspendida sobre el mar ha sido bautizada con el nombre oportuno y evocador de Plazuela Sargento Ibáñez” (Meza 73). Esta referencia textual presenta una ironía en dos niveles. En primer orden, y de manera evidente, un espacio destinado a la evacuación de fluidos corporales se nomina con el nombre del dictador; en segundo término, se propone una degradación militar de Carlos Ibáñez, pues el nombre del excusado es "Sargento Ibáñez”, vale decir, un soldado adscrito a la tropa, mientras que Carlos Ibáñez fue la autoridad máxima del cuerpo de Carabineros de Chile, es decir, su nombre está adscrito a los Oficiales de la institución.

El pensamiento y la escritura, por otro lado, se convierten en armas peligrosas para quienes ejercen el poder y dirigen la máquina punitiva en la isla-presidio: "el pensamiento, por el solo hecho de ser pensamiento, es un enemigo peligroso y hay que crucificarlo o fusilarlo contra un muro" (Meza 211). La escritura y la lectura están en interdicto en el campo Más Afuera, por eso todos los lápices son confiscados y puestos bajo resguardo policial:

La lectura, cuando no se trata del Boletín de Carabineros, es para el teniente una cosa inútil, perjudicial y aburrida. 
Dossier. Pablo Fuentes Retamal, Edson Faúndez Valenzuela. "UUna pausa de humanidad en medio de un horror infinito'. Eugenio González y Roberto Meza: prisioneros políticos en Isla Más Afuera"

$(\ldots)$

El Teniente (...) se muestra todo alterado y no oculta su inquietud porque nos ve escribiendo. Es el miedo instintivo al libro, el lápiz, la pluma. (Meza 88-90)

El prisionero Elías Lafertte es consciente de la importancia de la escritura, por lo que oculta algunos trozos de papel entre sus ropas: "ha prestado en la tarde un block pequeño que reserva para sus cartas íntimas y allí he copiado mis versos" (Meza 315). Los reclusos utilizan estas cuartillas para redactar un periódico manuscrito, cuyo único ejemplar circula de mano en mano y de lector en lector: "Ha redactado (Néstor Donoso) casi íntegro el número segundo de un periódico manuscrito que circula entre los políticos. Tiene un nombre que no puede ser olvidado: «Siempre»" (Meza 196).

Los prisioneros mantienen, además, una biblioteca clandestina y comunitaria. Los escasos libros que no fueron decomisados en los allanamientos descansan en un anaquel popular: "los confinados leen el tomo de Los miserables que hay en la cuadra de los (presos) políticos. Los libros son de todos" (Meza 190). Un volumen de esta biblioteca constituye un verdadero tesoro para los prisioneros, debido a los comentarios que fueron apuntados en sus hojas: "León Peña ${ }^{11}$ guarda como una reliquia (...) el ejemplar de $E l$ capital de Marx que perteneció a Luis Recabarren con las anotaciones que de su puño y letra hizo el jefe del comunismo chileno" (Meza 73).

El estudio es otra estrategia de resistencia. El abogado Néstor Donoso enseña a los obreros "las combinaciones del ajedrez y las sinuosidades de los códigos" (Meza 323), mientras que estos camaradas lo instruyen en el oficio de "zapatería" (Meza 323). Roberto Meza dicta clases de lengua y cultura francesa a un grupo de diez penados, entre quienes destaca el albañil Juan Chacón ${ }^{12}$, "sombrerero, y el mejor, o uno de los mejores, alumnos de francés del curso" (Meza 280).

El canto es un catalizador en el campo Más Afuera. Los prisioneros refuerzan sus convicciones cuando entonan melodías que portan contenido ideológico:

\footnotetext{
${ }^{11}$ Braulio León Peña. "Miembro del Comité Central del Partido (Comunista), encargado de trabajar en Valdivia y cubrir toda la zona sur del país" (Arcos 14).

12 Juan Chacón. Militante comunista. El escritor José Miguel Varas reconstruyó la vida de este obrero en la novela Chacón (1998). Este relato fue escrito, a partir de los testimonios de los camaradas que conocieron y compartieron la lucha política de este obrero.
} 
El 1 de mayo de 1927 los deportados más jóvenes quieren dar una sorpresa a sus compañeros y los despiertan al son de la Internacional. La canción de los anhelos proletarios enternece hasta las lágrimas a esos hombres que han conocido todas las formas del dolor y la miseria. (Meza 186)

Los prisioneros encuentran en las celebraciones íntimas oportunidades para resistir el imperio del horror. El prisionero Teodoro Brown ${ }^{13}$ homenajea con un humilde ramillete de flores a Roberto Meza en el día de su cumpleaños: "en la isla cumplo mis tristes veintinueve años (...) (Brown) trae un ramo de flores. ¡Flores en Más Afuera! Y lo deja colgando en la cabecera de mi tosco y pobre catre" (Meza 180).

El ácrata Félix López ${ }^{14}$ expresa las siguientes palabras cuando se decreta la liberación de un grupo de prisioneros: "Digan a los compañeros que (...) pregunten por nosotros, que nuestra salud moral y nuestra fe en el porvenir se mantienen inquebrantables" (Meza 314). Esta referencia explica el propósito de las estrategias de resistencia que desplegaron los prisioneros en Más Afuera, acciones de sobrevivencia que desafiaron los embates del poder para custodiar la integridad física y moral de los penados. Revela también la utopía de transformación social que habita en la escritura testimonial de Roberto Meza.

Más Afuera y Los trágicos días en Más Afuera. Testimonios sobre un espacio de horror, pero también de humanidad

Quizá no se pueda comprender todo lo que sucedió, o no se deba comprender, porque comprender casi es justificar.

Primo Levi, Si esto es un hombre.

Los testimonios de Eugenio González y Roberto Meza coinciden al describir algunas estrategias de resistencia que desplegaron los prisioneros en el campo Más Afuera. Se trata de acciones individuales y colectivas que orientan la instalación de una disciplina

\footnotetext{
${ }^{13}$ Teodoro Brown, militante ácrata. El escritor Manuel Rojas noveló parte de la vida de este dirigente en Sombras contra el muro (1964).

${ }^{14}$ Félix López. Militante anarquista. Participó activamente en la redacción y edición del periódico $L a$ protesta.
} 
Dossier. Pablo Fuentes Retamal, Edson Faúndez Valenzuela. "UUna pausa de humanidad en medio de un horror infinito'. Eugenio González y Roberto Meza: prisioneros políticos en Isla Más Afuera"

de trabajo, de autocuidado, de conservación de los otros y de creación de espacios de liberación momentánea, donde el baile, el canto y la risa ocupan un lugar de privilegio.

El ejercicio laboral permitió a los reclusos contrarrestar las horas de tedio y aburrimiento que les impuso el dispositivo carcelario. Más Afuera pormenoriza, en términos generales, las labores desarrolladas por los prisioneros. El narrador se limita a enumerar algunas actividades, evitando precisar las identidades de los responsables de cada tarea. El narrador de Los trágicos días en Más Afuera propone, en cambio, un relato minucioso que registra el nombre y las obligaciones que asumió cada recluso. De este modo, se indica, por ejemplo, que Daniel Mery atendió el reciclaje, Néstor Donoso se preocupó de los pasatiempos, Rogelio Gaete trabajó en la cocina y Roberto Meza cumplió labores en la panadería. En este punto parafraseamos a Norberto Flores y Adolfo Bisama para señalar que los seres que transitan por la bitácora del poeta Meza - detenidos y militares, torturadores y verdugos - no son "seres de papel", sino que personas con nombre y apellido, sujetos "reales", como decía Unamuno, dotados de una ominosa realidad (96).

Las labores productivas que realizaron los prisioneros son estrategias de resistencia que favorecieron la sobrevivencia, el autocuidado y el encuentro con el otro. De esta manera, se propicia una inversión de roles en la isla-presidio, pues los penados ejercen la disciplina en el campo, mientras que los carceleros son presentados como sujetos indisciplinados. Esta inversión resulta clave para comprender las características de la relación de fuerzas, así como de la resistencia al poder, y la emergencia de una promesa de país. Son los sujetos disciplinados (los reclusos) quienes están mejor capacitados para instaurar un orden justo y fraternal en un país regido por el autoritarismo dictatorial. Las escrituras testimoniales examinadas, por lo tanto, además de construir una imagen del "yo" en el marco de un territorio en cautiverio, deslizan una promesa (política) de un porvenir distinto para Chile. En este punto estamos con Emma Sepúlveda para señalar que el discurso testimonial exorciza la mudez y abre un espacio de reconocimiento, público y personal, que regresa la voz a aquellos sujetos cuyo silencio fue impuesto por la oficialidad (19).

La fraternidad es una consecuencia de las estrategias de resistencia que se destaca en ambos testimonios. Más Afuera describe, por ejemplo, los padecimientos de un prisionero tuberculoso y los auxilios que le otorgan sus camaradas de reclusión. El narrador 
oculta las identidades del enfermo y la de sus cuidadores, limitándose a nominar a estos personajes mediante seudónimos. Este mismo cuadro se detalla en Los trágicos días en Más Afuera, sin embargo, el narrador de este relato indica que Rogelio Gaete, militante anarquista, es el agonizante. Esta individualización no es gratuita, pues, tras la caída de Ibáñez, las víctimas del poder fundaron la "Asociación de los perseguidos por la Dictadura" (Délano 99). Así, el testimonio de Roberto Meza ofrece, en primer lugar, un relato sobre tiempos aciagos y, en segundo término, individualiza las identidades y militancias de las víctimas del poder totalitario.

El estudio es una estrategia de resistencia que se distingue en ambos testimonios. E1 narrador de Más Afuera vincula este recurso con los talleres de zapatería y carpintería que imparten los prisioneros en la isla. Siguiendo la tónica que sugiere este relato, no se revelan las identidades de los tutores ni las de los asistentes a estas capacitaciones. Por su parte, las páginas de Los trágicos días en Más Afuera nominan a los relatores de cada clase y puntualizan a los alumnos más aventajados en cada materia. Nos enteramos, así, que Néstor Donoso dicta el curso de ajedrez y la clase de leyes, mientras que Roberto Meza se encarga de enseñar lengua francesa a sus compañeros de reclusión. Es necesario subrayar el reconocimiento del narrador a las habilidades lingüísticas del obrero Juan Chacón, el estudiante más aventajado de la clase de francés. Consideramos que este gesto lo posibilita la fecha de publicación de Los trágicos días en Más Afuera, situada después de que el régimen dictatorial de Ibáñez había caído; de lo contrario, estos antecedentes habrían servido a la dictadura para completar el perfil de este obrero y facilitar las labores persecutorias.

La alegría y la risa son estrategias de resistencia que reconocemos en algunas actividades descritas en los testimonios de González y Meza. Más Afuera pormenoriza las fiestas y bailes que organizan los prisioneros, celebraciones que suspenden, momentáneamente, los límites de lo permisible, motivo por el que el texto de González se caracteriza por un despliegue mayor de los signos del deseo y del cuerpo. En este sentido, algunos prisioneros asumen roles femeninos en la pista de baile para transgredir las normativas que impone la autoridad militar. El relato de Meza convoca la risa, a propósito de una letrina que los prisioneros bautizan con el nombre Carlos Ibáñez. Los reclusos de 
Dossier. Pablo Fuentes Retamal, Edson Faúndez Valenzuela. "UUna pausa de humanidad en medio de un horror infinito'. Eugenio González y Roberto Meza: prisioneros políticos en Isla Más Afuera"

ambos testimonios saben que la risa es un arma corporal capaz de resistir las pretensiones de sus captores e invertir, por momentos, las relaciones de fuerza.

El canto es una estrategia de resistencia que libera las tensiones de los prisioneros. Un recurso descrito en ambos testimonios, pero con distintos matices. El relato de Eugenio González indica que el canto es un recurso convocado dentro del marco de las celebraciones organizadas por los penados en los pabellones. El narrador describe estos cantos sin ofrecer mayores antecedentes, su relato se limita a mencionar que estas melodías remiten al cancionero popular. El testimonio de Roberto Meza celebra bodas entre canto y política, actualizando los sueños de transformación social del narrador y de los reclusos, por eso, Los trágicos días en Más Afuera ilumina a los prisioneros más jóvenes, quienes entonan "La Internacional" dentro del marco de la conmemoración del Primero de mayo.

Las expresiones artísticas y culturales son claves en el contexto de las estrategias de resistencia descritas en los testimonios de González y Meza. Más Afuera refiere la fundación del "Conjunto teatral Isla de Más Afuera", asociación que promovió manifestaciones artísticas para convocar instancias de esparcimiento entre los penados. Estas expresiones culturales son variadas y no presentan contenido político, más bien apuntan al divertimento de la población penitenciaria. Los trágicos días en Más Afuera alude a actividades culturales que exigen mayor preparación, por ejemplo, la escritura de un periódico clandestino y la conformación de una biblioteca popular. Estas acciones evidencian el compromiso político de los prisioneros, ya que, se menciona la circulación de literatura de corte marxista en los pabellones de la isla.

El testimonio de Roberto Meza es tres veces más extenso que el relato de Eugenio González. Esta amplitud permite al narrador de Los trágicos días en Más Afuera describir algunas estrategias de resistencia que no se encuentran en Más Afuera. Nos referimos, puntualmente, a las estrictas normas de higiene que mantienen los prisioneros y la sagacidad de los cocineros para lidiar con la escasez de alimentos: formas de resistencia que remiten al autocuidado y al despliegue de una sensibilidad en pugna con la deshumanización que persigue el ejercicio del poder.

Más Afuera y Los trágicos días en Más Afuera ofrecen, con todo, distintas perspectivas para un mismo acontecimiento de horror. El relato de Eugenio González es una narración cuyo foco narrativo está puesto en los reos comunes de la isla, mientras que 
el testimonio de Roberto Meza se construye desde la mirada de los prisioneros políticos. Esto es significativo en la medida que González construye un bloque con el grupo más marginal (los comunes), estableciendo una distancia respecto del grupo que identifica a Meza (los prisioneros políticos). Los sentidos de los sueños del porvenir que estos testimonios generan deben considerar estas alianzas políticas.

Otro aspecto relevante. Más Afuera presenta a la población penal sin precisar nombres ni militancias políticas, tampoco revela las identidades ni la adscripción militar de los carceleros. Estas precauciones se justifican, como ya se ha sugerido, luego de considerar que Eugenio González publicó su testimonio en 1930, vale decir cuando el régimen de Ibáñez aún ejercía el poder. El narrador de Los trágicos días en Más Afuera asume privilegios narrativos que, tiempo atrás, serían impensados. Este testimonio, publicado en 1931, tras la caída de la dictadura, revela identidades y militancias, indica el nombre de los carceleros, su gradación y filiación militar. Información que antes no habría tenido cabida, pues, como ya lo planteamos, comprometería seriamente a su autor y a quienes fueron puntualizados en este testimonio.

Es necesario señalar que el vínculo amical que cultivaron Eugenio González y Roberto Meza se quebró en Más Afuera. El teniente Eduardo Palma solicitó a Eugenio González cooperar en la revisión de la documentación administrativa de la isla, a cambio de una litera individual alejada de los pabellones que albergaron a la población penal (Meza 119). Roberto Meza consideró que este pacto fue una traición, pues creyó poco ético acordar privilegios con el poder a espaldas de los prisioneros políticos. Debido a esta contrariedad, Meza puso fin a su amistad con González, a quien acusó de ser "amanuense de un verdugo" (Meza 119). Eugenio González reconoció su convenio con la autoridad militar, sin embargo, indicó que esta interpretación de sus actos es "subjetiva e inspirada por el resentimiento" (cit. en Meza 126).

Mencionamos que Eugenio González establece en Más Afuera una "alianza cifrada" con los reos comunes de la isla, sujetos infames cuyas existencias estaban condenadas al olvido, en términos de Foucault, este testimonio exhorta las semblanzas de aquellos prisioneros que congregan "la parte más nocturna y más cotidiana de la existencia" (La vida 89). En este sentido, el relato de Eugenio González despliega un dispositivo que vindica aquellas formas mínimas de vida que, de otro modo, habrían padecido a una doble condena: 
Dossier. Pablo Fuentes Retamal, Edson Faúndez Valenzuela. "UUna pausa de humanidad en medio de un horror infinito'. Eugenio González y Roberto Meza: prisioneros políticos en Isla Más Afuera"

el destierro y el olvido. Asimismo, en la medida en que Eugenio González ejerce su labor testimoniante, favorece una "construcción retórica del yo" que encuentra un correlato en sus posteriores discursos parlamentarios ${ }^{15}$. El senador González reiteró, en 1949, su preocupación por los hombres comunes, sujetos a los que iluminó para que expongan sus miserias, y exijan "por sí mismos, el remedio de sus males" (cit. en Contreras 201).

Consideramos que Más Afuera y Los trágicos días en Más Afuera son relatos que hacen audible las voces de las víctimas del poder totalitario y que re-construye una imagen del sujeto testimoniante que evidencian la capacidad de la literatura para resistir y abrir pasajes de vida, incluso allí donde impera el mal, para revisitar el pasado y desplegar la lucidez necesaria para examinar el presente y soñar un porvenir sin los signos de negatividad que afectaron a tantas vidas humanas.

\section{REFERENCIAS}

Agamben, Giorgio. Lo que queda de Auschwitz. El archivo y el testigo (Homo sacer III). Pre-textos, 2005.

Arcos, Humberto. Autobiografía de un viejo comunista. Lom, 2015.

Brescia, Maura. Selkirk-Robinson: El mito. Mare Nostrum, 2014.

Concha, Edmundo. "Los desterrados de Ibáñez”. La Nación, 10 de julio de 1997, p.43.

Contreras, Hernán. Eugenio González Rojas. Pensamiento vigente: disjecta membra. Pequeño Dios Editores, 2011.

Délano, Luis. Memorias. Aprendiz de escritor. Pluma y pincel, 1994.

Flores, Jorge. La dictadura de Ibáñez y los sindicatos (1927-1931). Dirección de Bibliotecas, Archivos y Museos, 1993.

Flores, Norberto y Bisama, Adolfo. El relato testimonial chileno. Ril Editores, 2017.

Foucault, Michel. "No al sexo rey. Entrevista por Bernard Henry-Levy". Un diálogo sobre el poder. Altaya, 1994, pp.146-164.

---. La vida de los hombres infames. Altamira, 1996.

---. Vigilar y castigar. Siglo veintiuno, 2002.

Fraiman, Juan. "Algunas consideraciones sobre el concepto de trabajo en Karl Marx y el análisis crítico de Jürgen Habermas". Trabajo y sociedad, núm. 25, 2015, pp. 235 245.

Gómez, Andrés. Más Afuera. La Tercera, 10 de agosto de 1997, p.53.

González, Eugenio. Más Afuera. Nascimiento, 1930.

Klein, Irene. La ficción de la memoria. La narración de historias de vida. Prometeo, 2007. Meza, Roberto. Los trágicos días en Más Afuera. Lom, 2006.

\footnotetext{
${ }^{15}$ Eugenio González fue electo Senador de República por la Cuarta Agrupación Provincial Santiago en 1949. Mantuvo ese cargo hasta 1957.
} 
Levi, Primo. Si esto es un hombre. Aleph, 2006.

Montero, René. La verdad sobre Ibáñez. Zig-zag, 1952.

Noemí, Daniel. Revoluciones que no fueron: ¿Arte o política?. Cuarto propio, 2013.

Prada, Renato. "De lo testimonial al testimonio. Notas para un deslinde del discurso testimonial". Testimonio y literatura. Institute for the study of Ideologies and Literatura, 1986, pp.7-21.

---. El discurso-testimonio y otros ensayos. Unam, 2001.

Rancière, Jacques. Política de la literatura. Libros del Zorzal, 2011.

Sarlo, Beatriz. Tiempo pasado. Cultura de la memoria y giro subjetivo. Una discusión. Universidad de Talca, 2003.

Sepúlveda, Emma. El testimonio femenino como escritura contestataria. Asterión, 1995.

Tapia, Carlos. "Más Afuera". Cuadernos del avión rojo, núm.6, 1998, pp.105-102. 